\title{
LABORATORY EXPERIMENT ON CROSS-SHORE BARRIER SPIT EVOLUTION BY STORM DYNAMICS
}

\begin{abstract}
Nguyen Xuan Tinh ${ }^{1}$, Magnus Larson ${ }^{2}$, Chantal Donnelly ${ }^{3}$, and Hitoshi Tanaka ${ }^{4}$
Every year there are many severe storms occurring around the world, in general, and in Japan, in particular. The occurrence of storms is expected to increase because of the global warming effects. An increasing wave height together with a rising mean water level during a storm create a high possibility for waves to overtop the beach crest causing a lot of sediment to be eroded to offshore areas or deposited in the inland direction. The study of the barrier island response to storms has therefore become very important in terms of sediment transport and beach morphology change, as well as damage to nearshore structures due to runup overwash and inundation overwash. However, changes in the beach profile and prevailing sediment transport mechanisms during a real event are difficult to obtain. Thus, laboratory studies are necessary to conduct. This study presents a laboratory experiment on the impact of storms on a sandy barrier islands. The main aim is to investigate the entire barrier island (or sand spit) response due to storm conditions considering the increase in water level due to storm surge. Also, further development of an analytical model for barrier profile change caused by runup overwash is presented and obtained results overall captured orderof-magnitude barrier face retreat and volume changes after the storm.
\end{abstract}

Keywords: laboratory experiment, washover sediment, cross-shore evolution, storm impact, barrier island

\section{INTRODUCTION}

Every year several hurricanes and severe storms impact the coastlines around the world, in general, and in Japan, in particular. Large wave heights together with the increase of water level during these extreme events create high likelihoods for overwash occurrence on low barrier islands or sand spits. In addition, the occurrence of overwash is expected to increase because of sea level rise due to the global warming effects and diminished sediment supply along many coasts. On populated barrier islands, overwash may damage bridges or simply render roads impassable due to large depths of deposited sand. Overwash can lead to coastal breaching when the overwashing waves and currents open new inlets on barrier islands.

It is extremely difficult to conduct measurements on the hydrodynamics and profile response during a real storm. Some good data sets have been collected, but most of them were surveyed several days, or even months, before or after storm. No measurements have been collected during the storm. Thus, to obtain data during a storm laboratory experiments are more suitable. There have been several laboratory studies regarding this topic, for example, Williams 1978, Hancock 1994, Kobayashi et al. 1996, Parachure et al. 1992, Baldock et al. 2004, and Tuan 2007. However, most of these studies are either focused on dune erosion due to storm or on breaching of barrier islands.

In the present study a laboratory experiment was carried out in a two-dimensional wave flume to in-depth investigate the sand barrier island cross-shore profile responses and to increase understanding of physical insight into sediment transport mechanisms in different zones of a barrier profile under a storm. The storm surge level and wave height were allowed to continuously increase and decrease in a manner similar to a real storm. The deposited sediment in the bay area was measured for each run using a sand trap. Barrier crest accumulation was shown to occur due to the runup overwash, and barrier lowering was caused by the inundation overwash. On the back of the barrier island, overwash hydrodynamics and sediment transport were shown to be affected by the bay water level, friction, infiltration, and lateral spreading.

An analytical model for predicting the response of a triangular beach profile to wave impact and overwash was first developed by Larson et al. (2009). However, this model can only reproduce the subaerial barrier profile response, but in fact the eroded part is often located some distance in the seaward direction. Hence, this model was further developed to take into account the submerged area until the water depth is equal to one half of the offshore wave height (an observation from the laboratory experiment). The result from validating the new model against the current laboratory data sets indicates that the model quite satisfactorily captured the volumetric response of the profile, but the barrier crest height was underestimated.

\footnotetext{
${ }^{1}$ Department of Civil Engineering, Tohoku University, 6-6-06 Aoba, Sendai 980-8579, Japan

${ }^{2}$ Department of Water Resources Engineering, Lund University, Box 118, S-221 00 Lund Sweden

${ }^{3}$ Swedish Meteorological and Hydrological Institute, 60176 Norrköping, Sweden

${ }^{4}$ Department of Civil Engineering, Tohoku University, 6-6-06 Aoba, Sendai 980-8579, Japan
} 
Prediction of overwash occurrence and modeling of barrier morphology changes due to storms can provide valuable planning information for local authorities, emergency services, and coastal residents.

\section{LABORATORY EXPERIMENT}

\section{Experimental set-up}

A series of experiments were carried out in a two-dimensional wave flume, as shown in Fig. 1. The length of the flume is $11.3 \mathrm{~m}$ with $50 \mathrm{~cm}$ height and $30 \mathrm{~cm}$ width. The flume was equipped with a monochromatic wave generator, a filter in front of the wave generator, and wave absorbing works at the other end of the flume to filter out reflected waves.

A typical triangular barrier island profile was prepared in the flume with a nearshore beach slope of $1 / 25$, sub-aerial beach slope of $1 / 4$, and backside barrier slope of $1 / 30$ covered by sand with a median grain size $\left(d_{50}\right)$ of $0.26 \mathrm{~mm}$, as shown in Fig. 1 . The total sediment volume in the wave flume was $80,000 \mathrm{~cm}^{3}$. Behind the barrier island there was a sand trap to measure the deposited sediment which was transported by overwash processes. The initial beach crest was made $150 \mathrm{~cm} \mathrm{long}$. A wave gauge was installed at the toe of the barrier slope to measure the wave conditions, which were assumed to correspond to the offshore waves. An extra small inflow/outflow valve was set at the bay side which allowed for continuously increasing or decreasing the water level in the wave flume.

A profiler, moving on the top of flume, was used to measure changes in the bed profile surface as seen in Photo 1 . This profiler was connected to a computer where the C-LOGGER application was installed for performing data sampling by using CONTEC Analog Input boards.

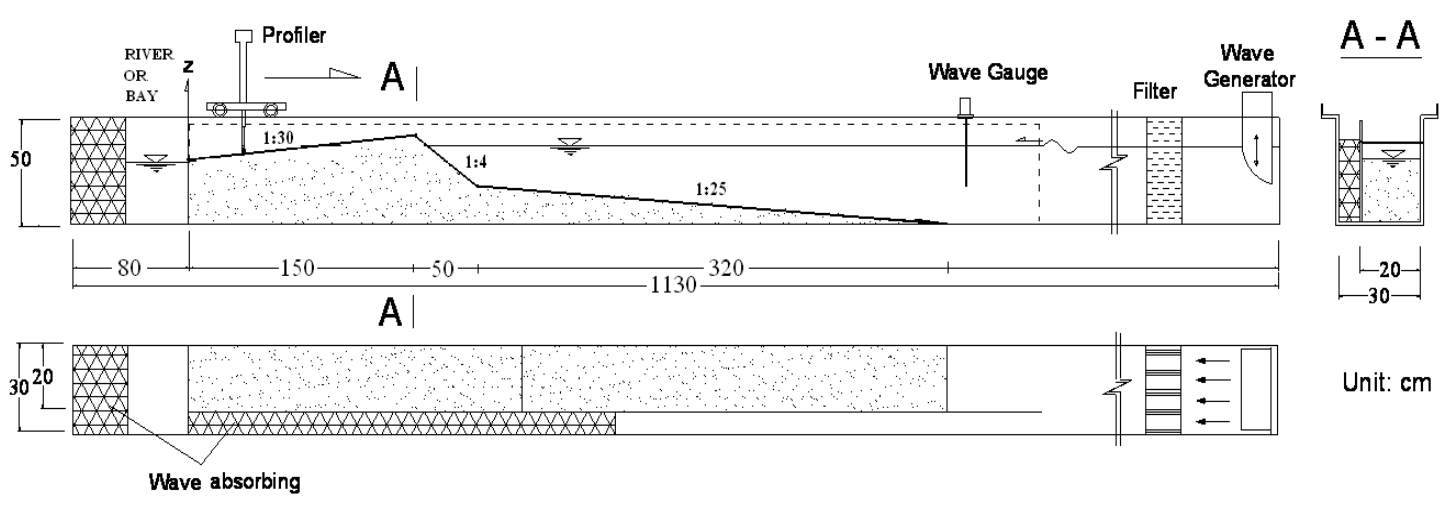

Figure 1. Experimental setup.

\section{Experimental initial cases}

The barrier island was tested in eight different cases (see Table 1) varying from natural conditions, where the wave does not overtop the beach crest, until the case of inundation overwash, in which the still water level is higher than the barrier crest. From Case 1 to Case 7, the water level was increased up to $1 \mathrm{~cm}$, respectively. Consequently, the wave height was raised from $7.2 \mathrm{~cm}$ to $8.0 \mathrm{~cm}$. The storm duration of these cases was set equal to 2 hours and the whole system was stopped at 10, 20, 30, 60, 90 and 120 minutes to measure the bed barrier island profile response.

In the storm condition case, the storm surge level was allowed to continuously increase and decrease, similar to real conditions, with storm duration of 8 hours, by using an extra inflow/outflow valve set at the end of the wave flume. As a result, the wave height was raised from $7.2 \mathrm{~cm}$ to $7.6 \mathrm{~cm}$. In this case, the system was stopped to measure the bed surface change as storm level increased or decreased $1 \mathrm{~cm}$ of height, which approximately took 1 hour.

Behind the barrier island there was a sand trap to measure the deposited overwashing sediment on the bay side. Table 1 shows the initial conditions for all experimental cases, in which WL is the water level, $H_{c}$ the beach crest height, $H_{0}$ the deepwater wave height, $T$ the wave period, and $t_{D}$ the storm duration. Furthermore, NC means the natural conditions, LRO is limited runup overwash, IO is the inundation overwash, and SC is the storm conditions. 


\begin{tabular}{|c|c|c|c|c|c|c|c|}
\hline \multicolumn{8}{|c|}{ Table 1. Experimental initial conditions. } \\
\hline & Name & $\begin{array}{c}W L \\
(\mathrm{~cm})\end{array}$ & $\begin{array}{c}H_{0} \\
(\mathrm{~cm})\end{array}$ & $\begin{array}{c}T \\
(\mathrm{~s})\end{array}$ & $\begin{array}{c}H_{c} \\
(\mathrm{~cm})\end{array}$ & $\begin{array}{c}d_{50} \\
(\mathrm{~mm})\end{array}$ & $\begin{array}{c}t_{D} \\
(\mathrm{~h})\end{array}$ \\
\hline CASE 1 & NC & 0 & 7.2 & 1.45 & 7 & 0.26 & 2 \\
CASE 2 & LRO & 3 & 7.5 & 1.45 & 4 & 0.26 & 2 \\
CASE 3 & RO-1 & 4 & 7.6 & 1.45 & 3 & 0.26 & 2 \\
CASE 4 & RO-2 & 5 & 7.7 & 1.45 & 2 & 0.26 & 2 \\
CASE 5 & RO/IO & 6 & 7.8 & 1.45 & 1 & 0.26 & 2 \\
CASE 6 & IO-1 & 7 & 7.9 & 1.45 & 0 & 0.26 & 2 \\
CASE 7 & OO-2 & 8 & 8.0 & 1.45 & 0 & 0.26 & 2 \\
CASE 8 & SC & $0-4$ & $7.2-7.6$ & 1.45 & $4.0-7.0$ & 0.26 & 8 \\
\hline
\end{tabular}

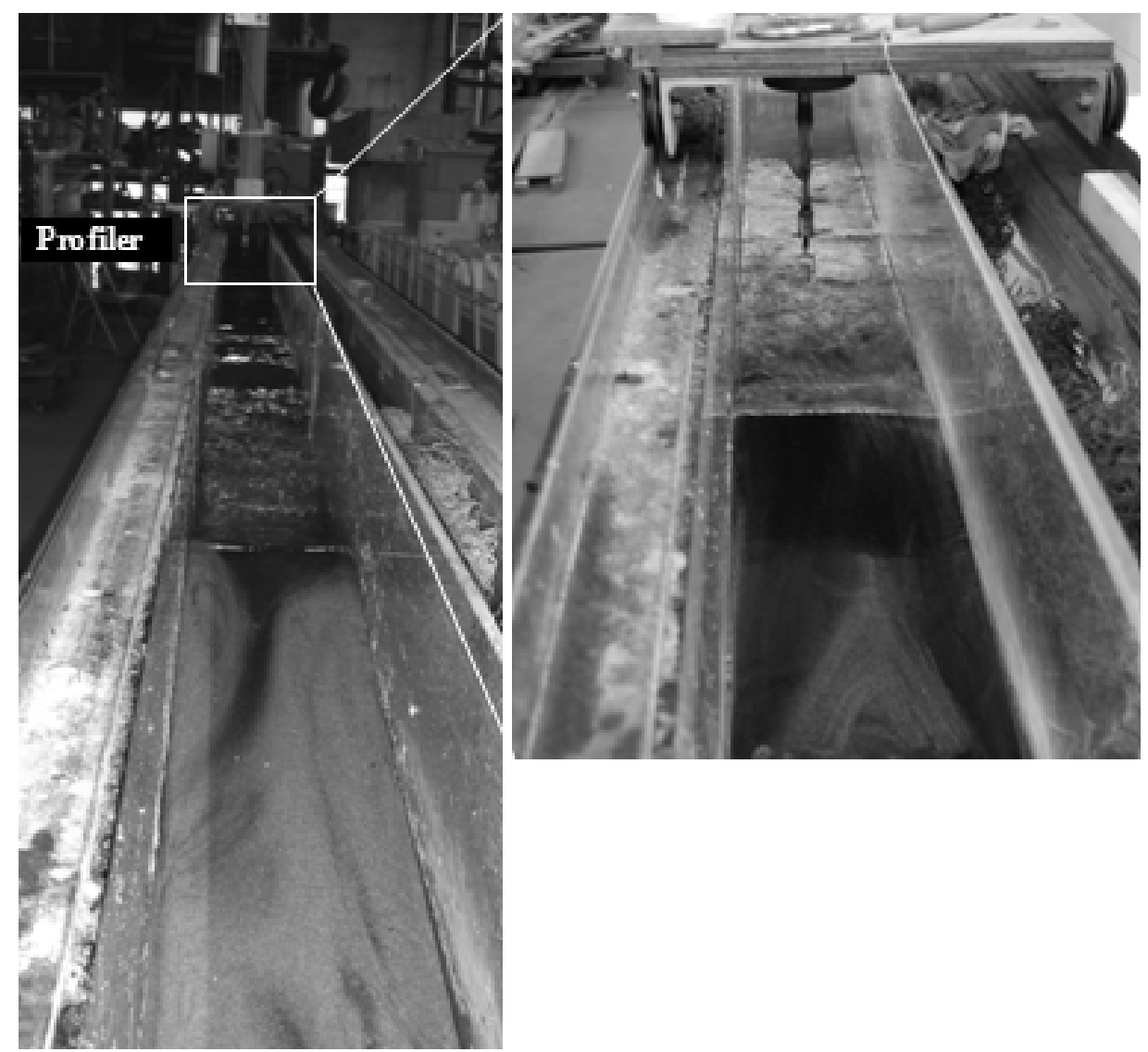

Photo 1. Profiler equipment.

\section{Experiment observation}

Wave height measurements

As mentioned above, a wave gauge was installed at the toe of the barrier to measure the monochromatic waves which were generated at the end of the flume. Fig. 2 shows a recorded sample of the offshore wave height.

Photo 2 shows snapshots of wave breaking at the barrier face and the bed elevation change. As waves are propagating to shallower areas they increase in height because of shoaling and then eventually break. Wave breaking generates turbulence and vertical fluid motion that cause sediment suspension and transport in either the onshore or offshore direction. At deeper locations, ripples form on the surface of bottom (Photo 2). 
Cross-shore profile measurements

The whole experimental system was stopped to measure the cross-shore barrier profile at 10, 20, $30,60,90$, and $120 \mathrm{~min}$ for case 1 to case 7 . In the storm case, however, the system was stopped as the water level rise up or down $1 \mathrm{~cm}$ in height, which took about 2 hours.

The aims of these tests were to investigate the effects of the water level rise itself, and runup overwash as well as inundation overwash, to barrier volume change and sediment transport during such extreme phenomenon. More description of these tests will be presented in the next sections. Fig. 3 shows the measurements of the cross-shore profile for all 8 cases studied.

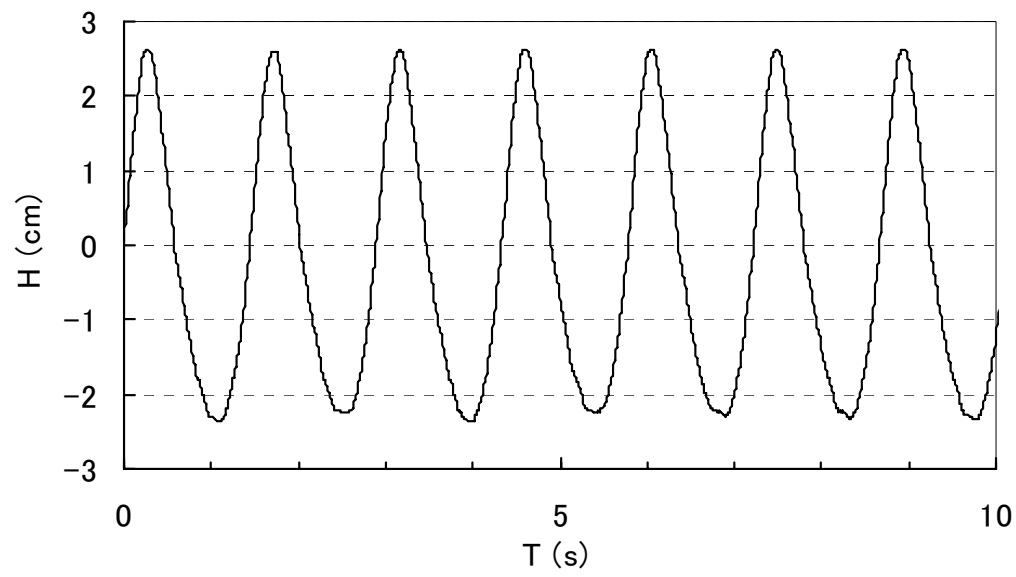

Figure 2. Measurement of the offshore wave height.
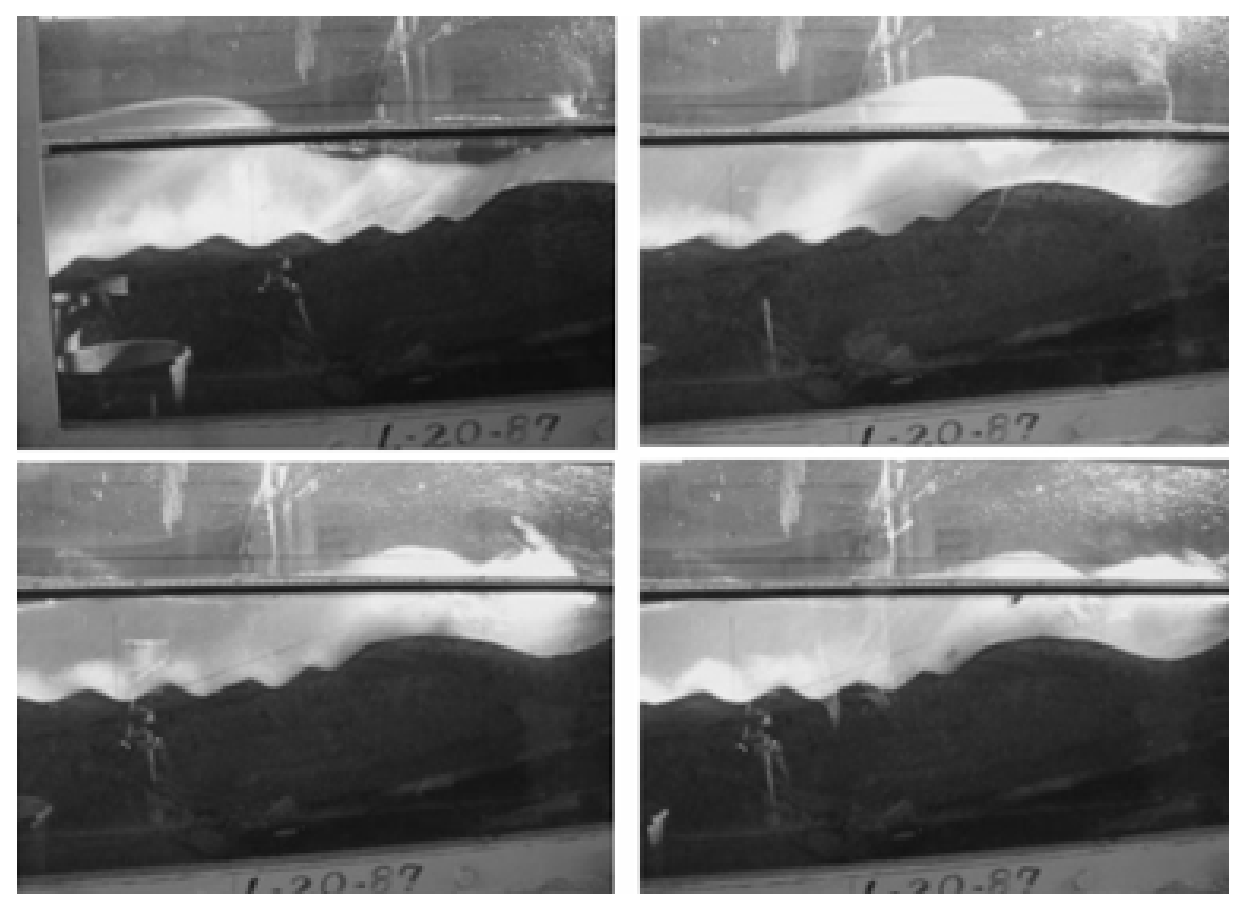

Photo 2. Snapshots of wave breaking and bed elevation changes during the experiment. 

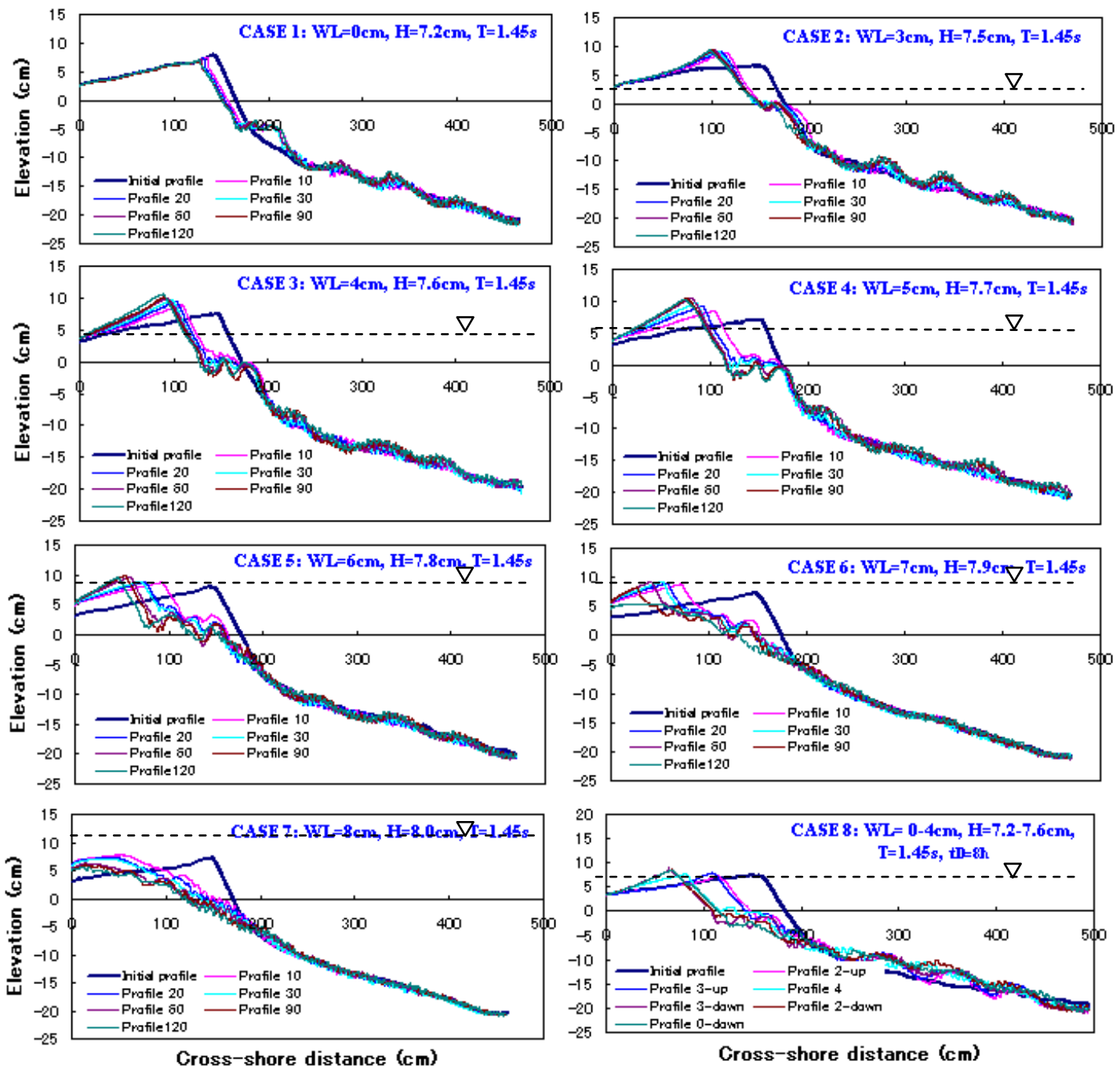

Figure 3. Time variation in the cross-shore beach profile for all cases studied (dashed line indicates the water level height elevation).

\section{EXPERIMENTAL RESULTS AND ANALYSIS}

In order to increase the physical understanding of cross-shore sediment transport, the measured cross-shore profiles were divided into four different zones, denoted as zone of bay deposition (Zone 1), washover deposition (Zone 2), barrier erosion (Zone 3), and offshore deposition (Zone 4). Through this division, the relationship between sediment transport and volume change in the different zones could be derived. The deposited and eroded sediment volumes were calculated by integrating the area between the pre- and post-storm profiles. The estimation of erosion and washover sediment deposits, as well as their extent, is significant for coastal management to plan for beach nourishment projects before and after a storm.

\section{Barrier crest height evolution}

The evolution of the barrier crest height and location also need to be analyzed in order to see the impacts of a storm on the beach. The variation in crest location and time evolution of barrier crest height for all cases are illustrated in Figs. 5 and 6, respectively. Under natural conditions, the beach face was eroded by wave action causing lowering of the barrier crest. However, the beach crest is often accumulated for the runup overwash cases. The larger the wave runup height is, the further the crest will be transported in the inland direction (Fig. 5). The accreted sediment on the top of the barrier might stop waves from overtopping the beach crest in the limited runup overwash case. 
In the beginning of inundation overwash, the beach crest is a little bit higher, but it then quickly decreases because of the second breaking occurring due to a sand bar forming in the nearshore. A lot of deposited sediment was obtained on the bay side area in the inundation case.

During the storm condition, two phases were observed. When the storm surge was low the waves were just hitting the beach face and the barrier crest was reduced in height, but when the storm surge was rising and the wave height was high enough runup overwash occurred and sediment deposited on the top of barrier, as can be seen in Fig. 6 .

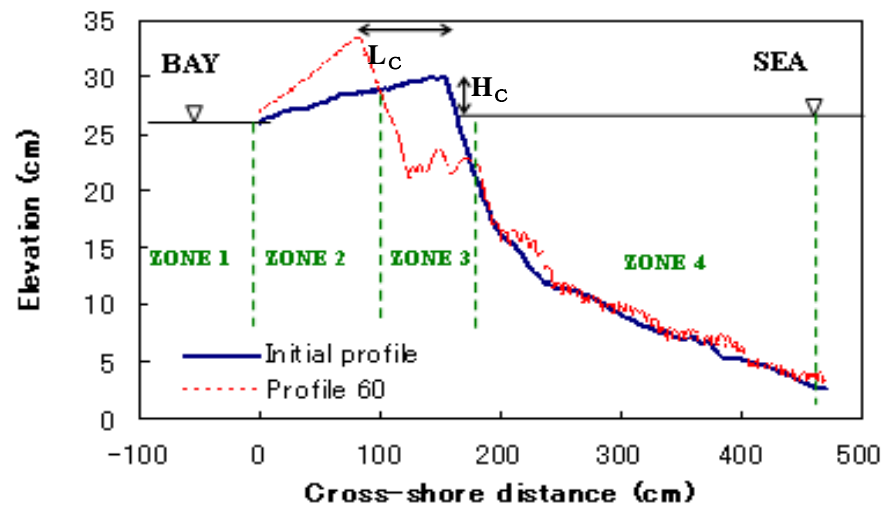

Figure 4. Definition sketch for typical barrier profile zones.

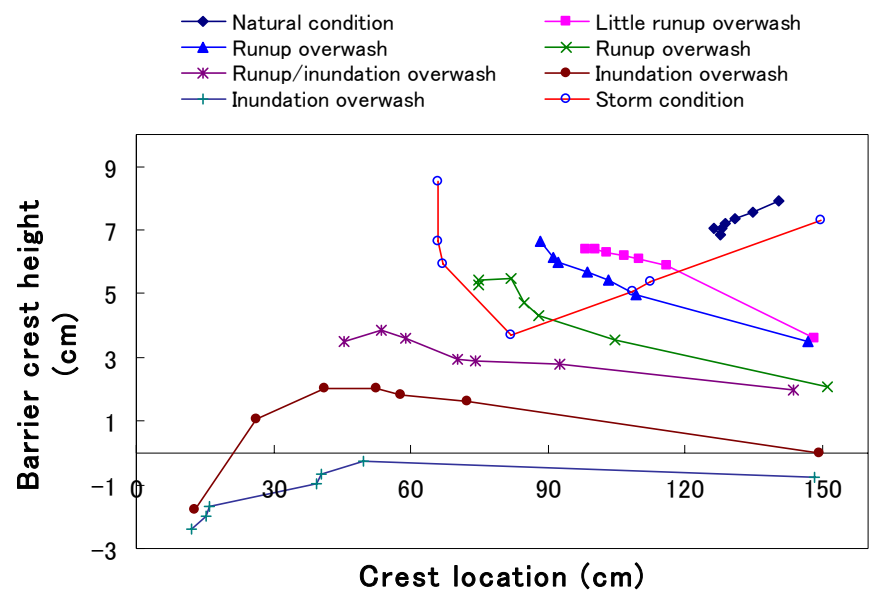

Figure 5. Barrier crest location evolution for all cases.

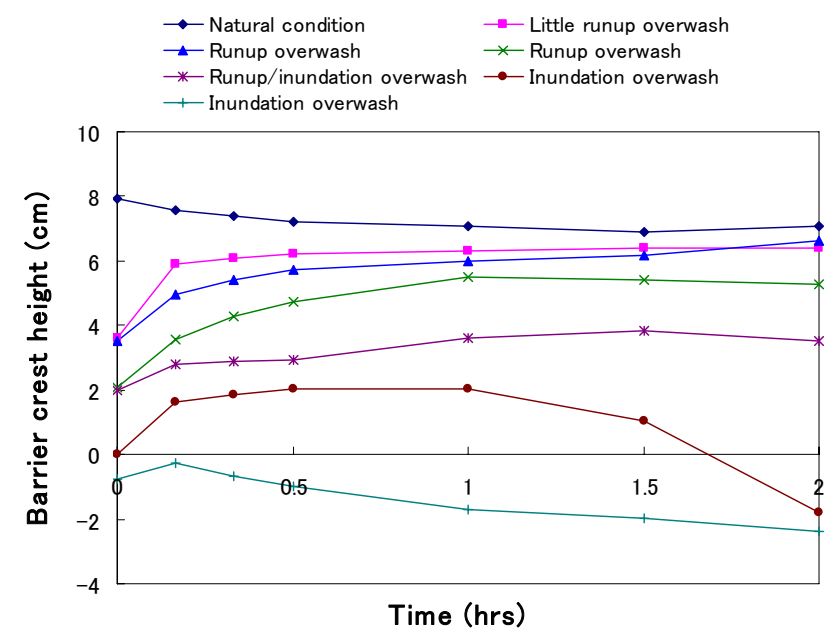

Figure 6. Time evolution of barrier crest height. 


\section{Volumetric sediment changes of cross-shore profile}

Sequential bed surface profile records can be analyzed to determine volumetric sediment changes throughout an area of interest, or to simply determine a net change in sediment depth at a specific location over time (Byrnes et al., 1987; and van der Wal and Pye, 2003). The volumetric sediment change is calculated by integrating the area between two consecutive profiles. Figs. 7 and 8 are the results of volumetric change in the measured profiles at time, $t$, compared to the initial profile, for inundation overwash-1 (Case 6) and storm condition (Case 8) as examples, respectively. The positive values indicate deposition areas and the negative values erosion areas.

Fig. 9 shows the time evolution of deposited and eroded sediment volume for the first seven cases. Basically, it is the positive and negative areas referenced to the zero line. The results illustrated that the eroded sediment volume is increasing with time during the natural and runup overwash cases and deposited on the landward or seaward sides. However, during the inundation cases, an interesting phenomenon was observed where most of the eroded sediment from barrier face was transported and deposited on the backside of the barrier island or even reached to the bay and river side (Fig. 9). This might be because the effects of bottom shear stresses in deeper water areas are less compared with shallower areas.

Washover deposition is the sediment that carried by runup/inundation overwash processes. Fig. 10 shows the volumetric sediment changes for the storm condition. The washover sediment starts to occur after two hours until 5 hours and remained high to the end of storm. After 5 hours, the wave was terminated due to the sediment deposition on the crest.
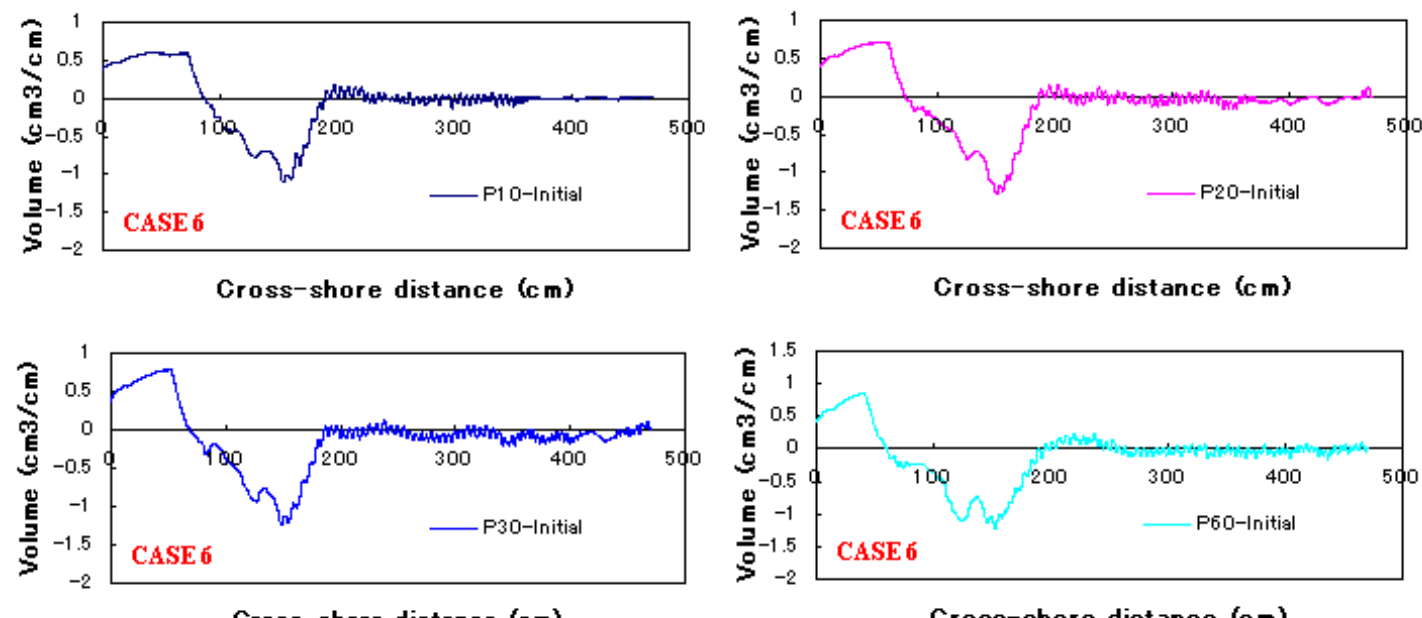

Gross-shore distance $(\mathrm{cm})$

Cross-shore distance $(\mathrm{cm})$
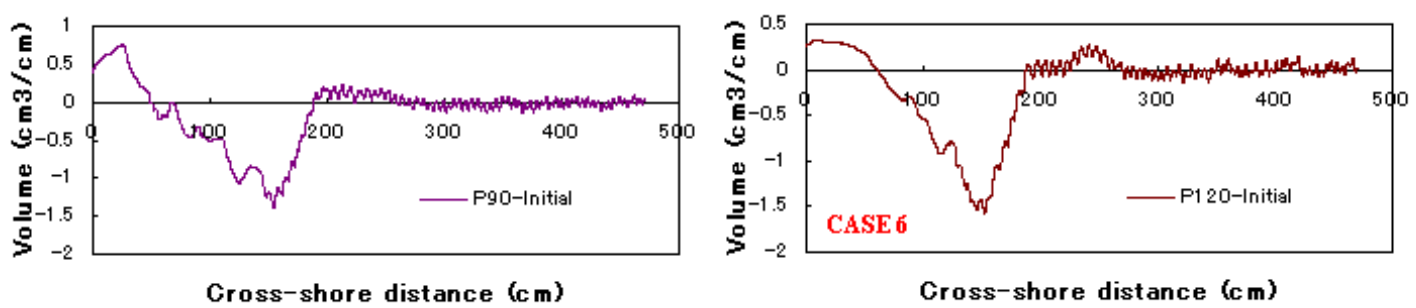

Figure 7. Cross-shore sediment volume change for Case 6: IO-1. 


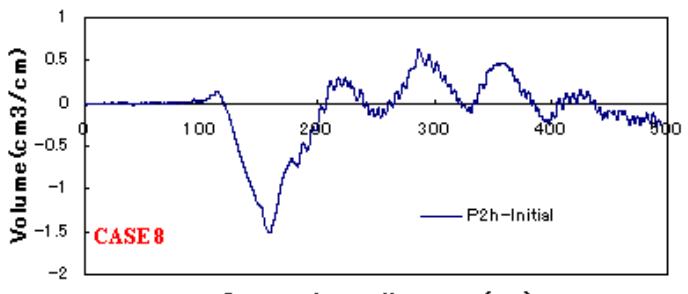

Cross-shore distance $(\mathrm{cm})$
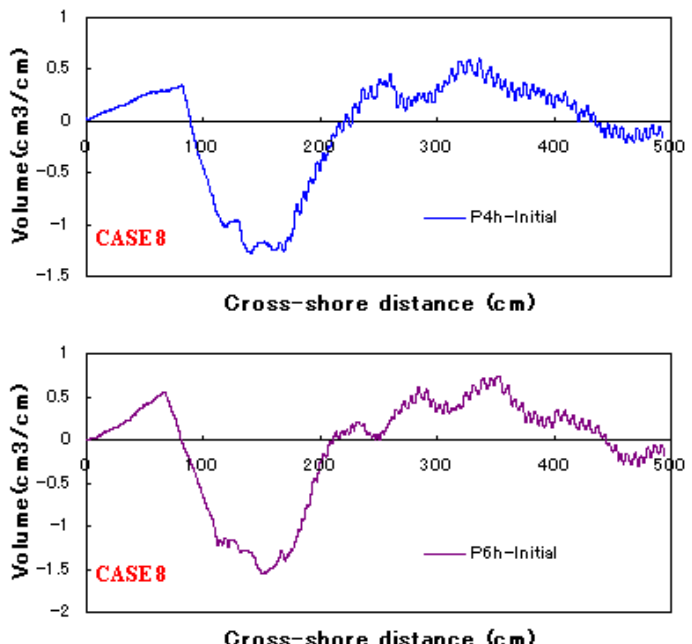

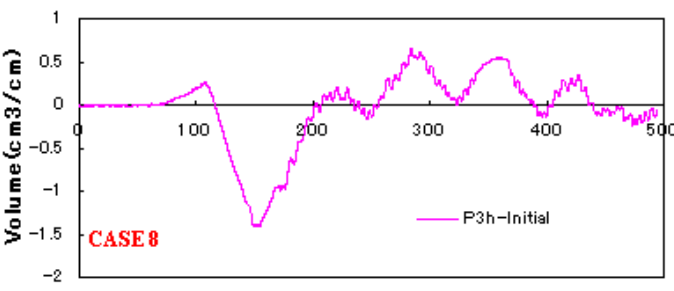

Cross-shore distance $(\mathrm{cm})$
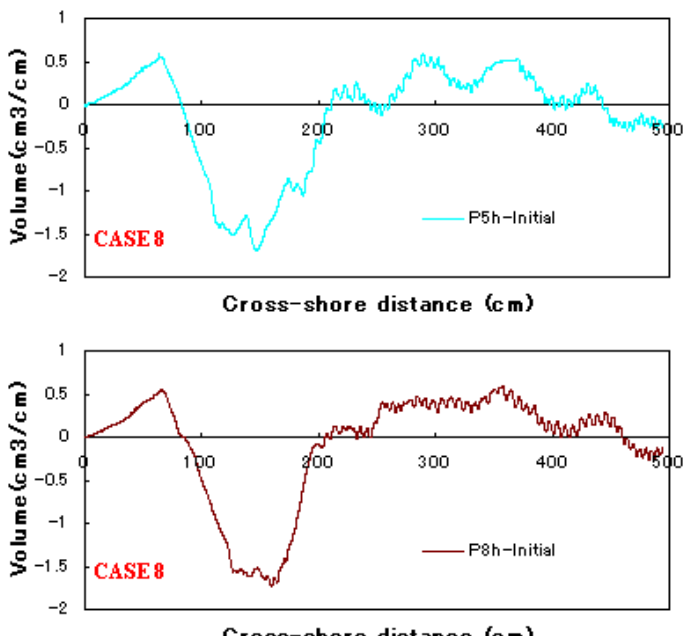

Cross-shore distance $(\mathrm{cm})$

Figure 8. Cross-shore sediment volume change for Case 8: Storm condition.

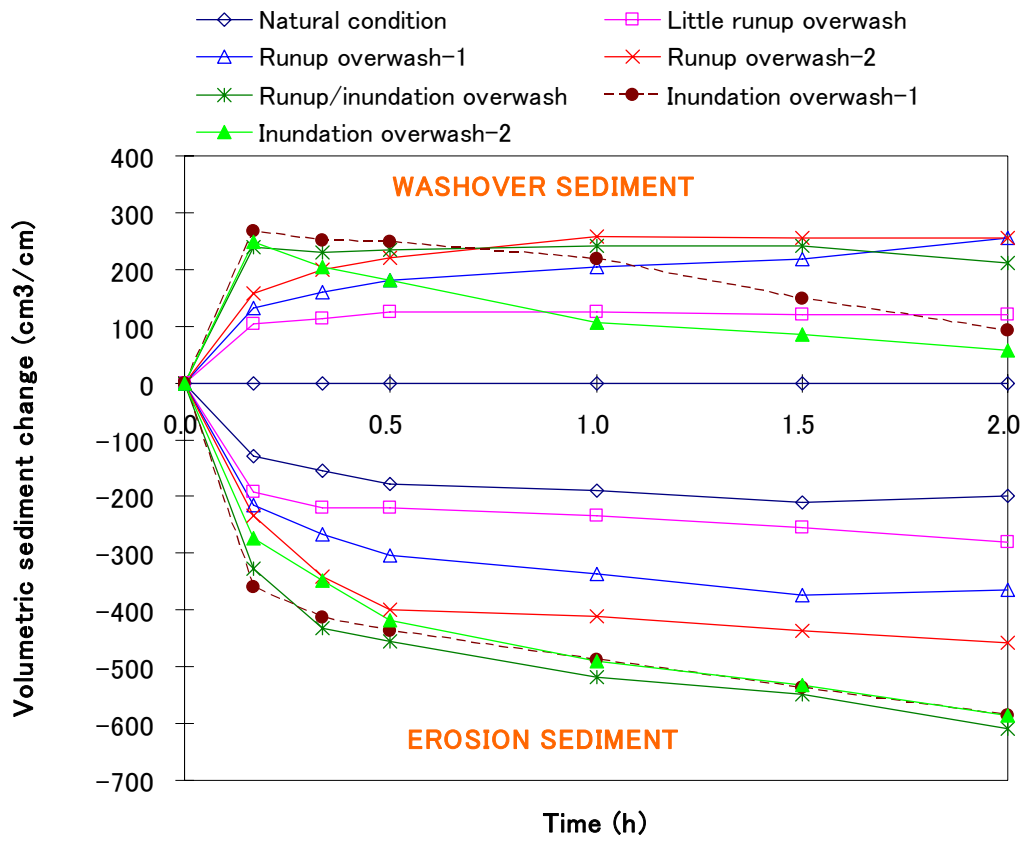

Figure 9. Time evolution of washover and erosion sediment volume for Case 1 to Case 7. 


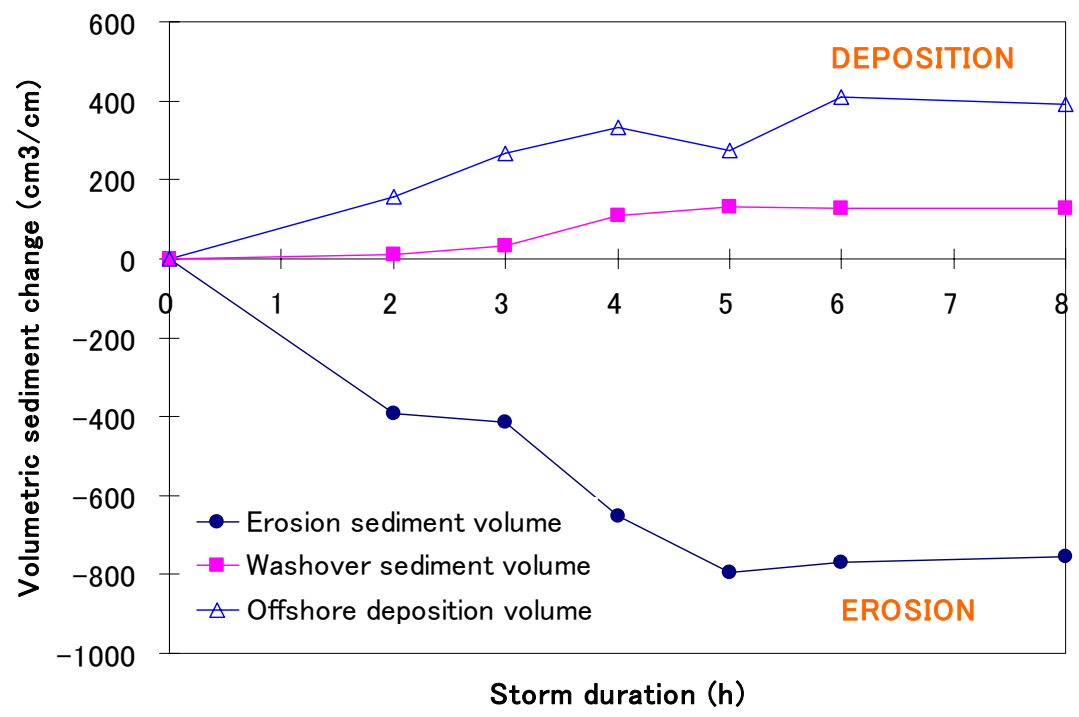

Figure 10. Time evolution of deposited and eroded sediment volume for Case 8.

\section{Cross-shore sediment transport rates}

Cross-shore sediment transport occurs in both the offshore and onshore directions. In the relative short time of storm condition the cross-shore sediment transport becomes very important. The incident wave energy was dissipated in front of the barrier causing sediment transport. The distribution of sediment transport rate has specific property in time and space in the area. The sediment transport rate distributes along the cross-shore section depending on the actions of wave and current. The conservation equation for sediment volume can be expressed as follows,

$$
\frac{\partial h}{\partial t}=-\frac{1}{(1-\varepsilon)} \frac{\partial q}{\partial x}
$$

where $h(x, t)$ is the bed elevation, $q(x, t)$ is the local net transport rate, and $\varepsilon$ is sediment porosity.

In order to determine the sediment transport rate from the changes in bottom elevation, an average net distribution of the cross shore transport rate is obtained for the elapsed time between two successive measured profiles. The net cross shore transport rate can be obtained by integrating the volume conversation equation between two cross-shore profiles as follows,

$$
q(x)=-(1-\varepsilon) \int_{x_{0}}^{x} \frac{\Delta h}{\Delta t} d x
$$

where $x_{0}$ is the shoreward location of no profile change, $\Delta h$ the changes of profile elevation during the time of $\Delta t$.

Figs. 11 and 12 show the time variation in net cross-shore sediment transport rates in different zones of Cases 6 and 8, respectively, where q10, q20, q30, q60, q90, and q120 is the sediment transport rate at 10, 20,30,60,90, and 120 minutes, respectively. In most of the cases, the sediment transport rate during first ten minutes is relatively high, and a lot of sediment goes to the onshore and offshore directions. However, the sediment transport rate will be smaller when the profile is approaching an equilibrium state. 

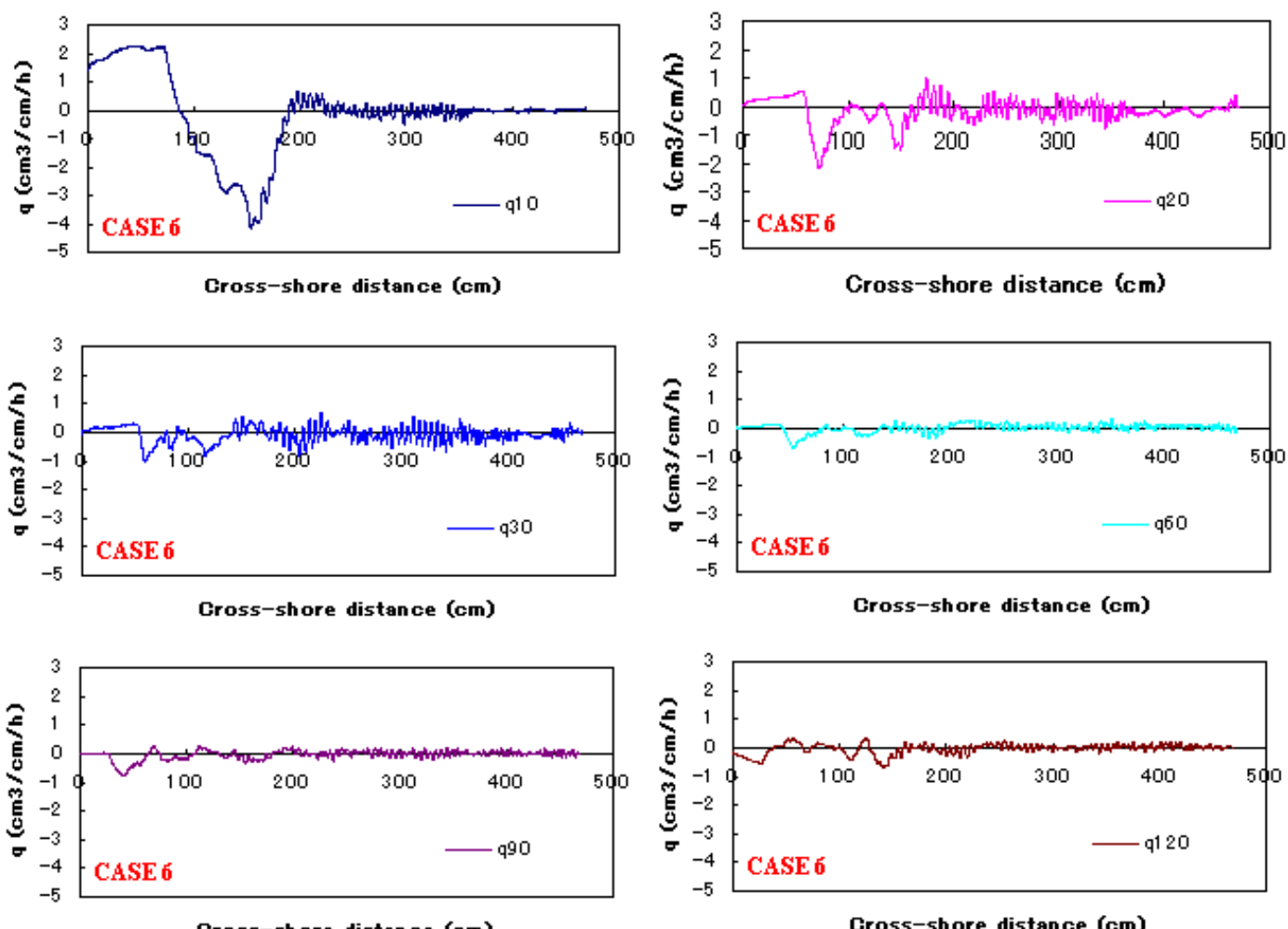

Gross-shore distance (cm)

Gross-shore distance $(\mathrm{cm})$

Figure 11. Time variation of cross-shore sediment transport rate for Case 6 .
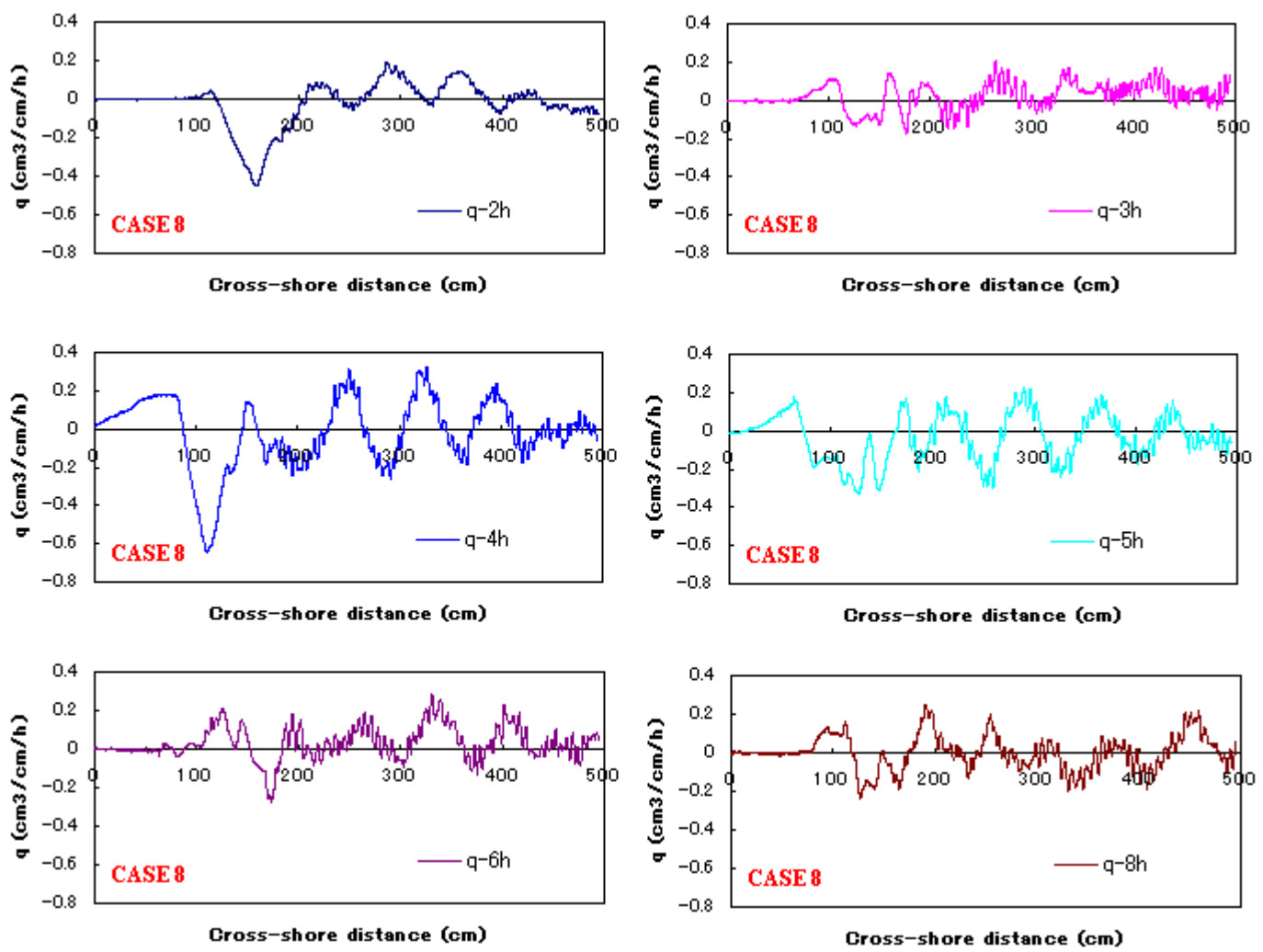

Figure 12. Time variation in cross-shore sediment transport rate for Case 8. 


\section{Relationship for sediment transport rate in different zones}

In this section, attempts are made to derive quantitative relationships of sediment transport rate related to the storm dynamics. The ratio of eroded sediment rate over washover sediment rate was plotted against the relative barrier crest height, $H_{C} / R$ (freeboard). The coefficient obtained is equal to 2.74, which is quite similar to what was found by Donnelly (2008) as shown in Fig. 13.

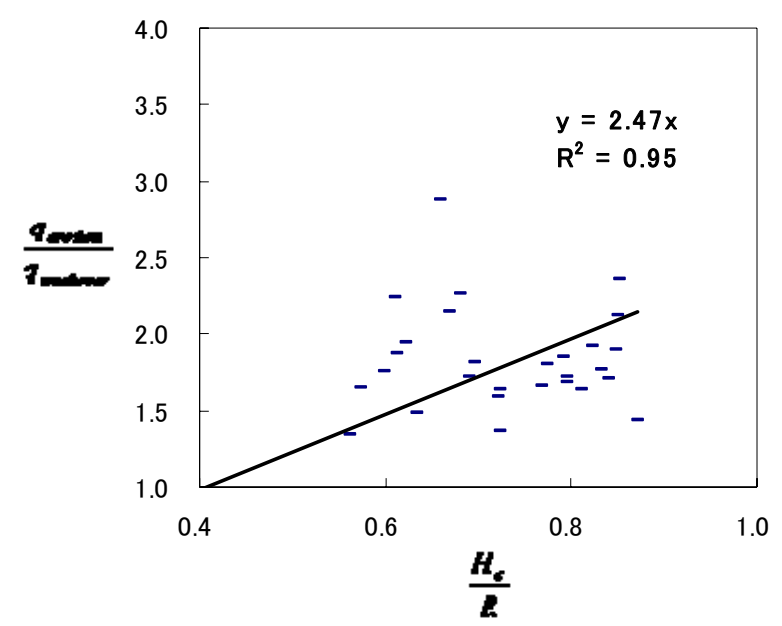

Figure 13. The ratio of total eroded sediment rate and washover sediment rate versus the relative barrier crest height.

The estimation of erosion and washover sediment deposits, as well as their extent, is significant for coastal management to plan for beach nourishment projects before and after a storm. The relationship between washover sediment rate and erosion rate is shown in Fig. 14. The eroded sediment volume rate, $q$, is approximately equal to 1.48 times the washover sediment volume rate, $q_{B}$.

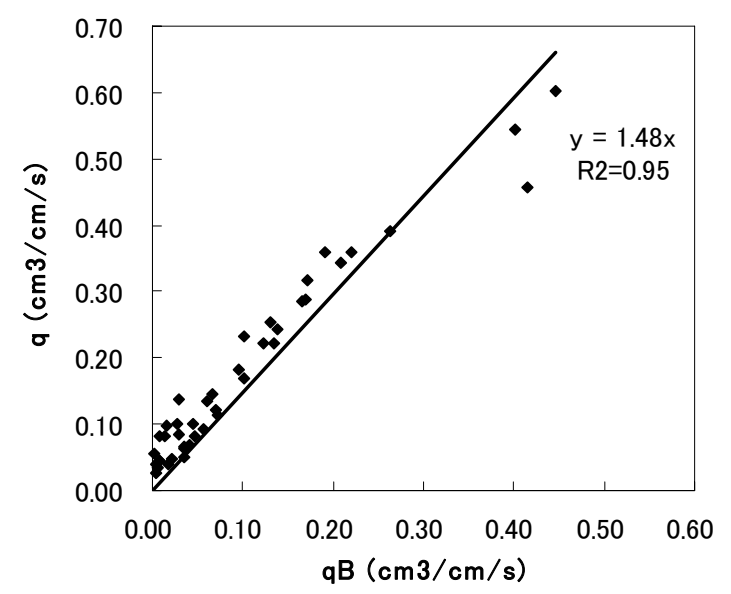

Figure 14. Relationship between erosion and washover rate.

\section{ANALYTICAL MODEL}

\section{Model development}

An analytical model for predicting sub-aerial profile response caused by wave overwash was first developed by Larson et al. (2009). However, this model reproduces order-of-magnitude subaerial barrier profile response, whereas the eroded part of the underwater profile often located some distance in the seaward direction (Chapter III-3 in CEM2002) is not included. In addition, the washover sediment may also be transported into the bay at a certain water depth by the gravity forces. The observations from the experimental cases on runup overwash (Cases 2, 3, 4 and 5) are that the water 
depth of the eroded part was approximately equal to one half of the deepwater wave height. Hence, further development of the analytical model to take into account the submerged area is presented in this study.

A detailed explanation about the analytical model can be found in Larson et al. (2009). This paper just presents details of the improvements. Basically, the barrier island is assumed to have a triangular shape. Fig. 15 shows a definition sketch of schematized triangular of barrier profile responses to runup overwash. This triangular is defined by three different points known as the seaward location $\left(x_{00}^{\prime}\right)$ at $H_{0} / 2$ water depth, landward location $\left(x_{B 0}^{\prime}\right)$ at $H_{0} / 2$ water depth, and barrier crest location $\left(H_{c 0}\right)$ refers to the still-water level (SWL).

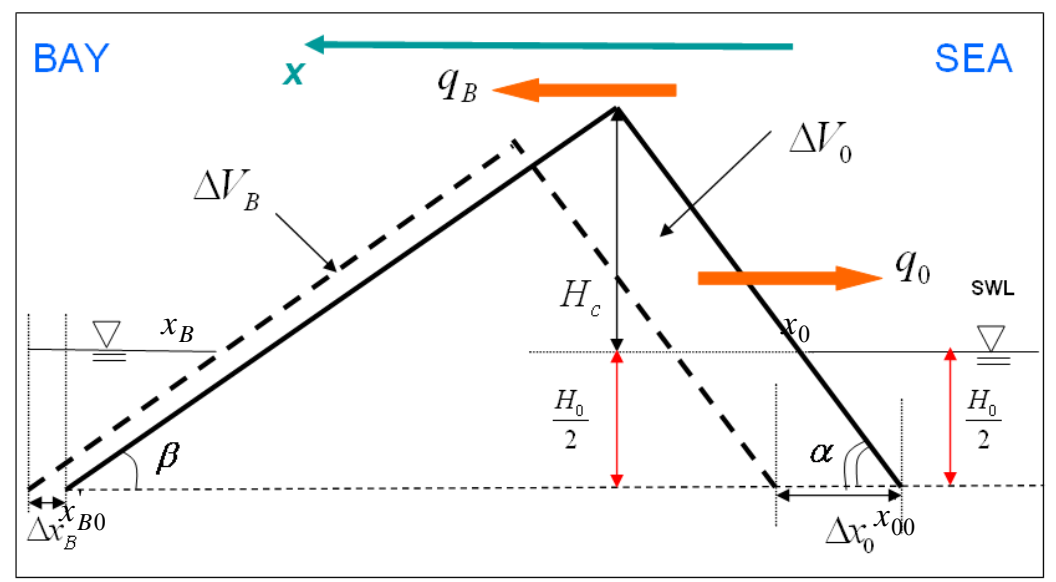

Figure 15. Definition sketch for a triangular barrier island subjected to overwash.

Then, the new locations of the seaward and landward points at $H_{0} / 2$ water depth are, respectively,

$$
\begin{aligned}
& x_{00}^{\prime}=x_{0}-\frac{H_{0}}{2 \tan \alpha} \\
& x_{B 0}^{\prime}=x_{B}+\frac{H_{0}}{2 \tan \beta}
\end{aligned}
$$

in which: $x_{0}, x_{B}$ are the locations of the seaward and landward SWL, $\alpha, \beta$ are the slopes of the barrier face and the back barrier, respectively, and $H_{0}$ is the offshore wave height.

If we assume that runup overwash occurs, then the volume of sediment, $\Delta V_{o}$, is mobilized by wave impact over a period of time, $\Delta t$. A part of this mobilised sediment volume, $\Delta V_{B}$, is deposited subaerially on the back barrier and bay, while the rest, $\left(\Delta V_{o}-\Delta V_{B}\right)$, is eroded towards the offshore direction. Assuming $\Delta t$ approaches zero, the sediment eroded from the profile, $\Delta V_{o}$, may be expressed in terms of the seaward and landward sediment transport rates, $q_{o}$ and $q_{B}$, respectively. Using the conservation equation for sediment volume, analytical equations to calculate the time evolution of the triangular beach were derived for known $q_{B}$, and $q_{0}$.

By using the triangular geometric relationships and conservation equations for sediment volume, the analytical solution for time evolution of the triangular beach in terms of the initial conditions as well as seaward and landward sediment transport rates can finally be expressed as:

$$
H_{c}=H_{c 0} \sqrt{1-\frac{q_{0} t}{V_{D 0}}}-\frac{H_{0}}{2}
$$




$$
\begin{gathered}
x_{0}^{\prime}=x_{0}-\frac{H_{0}}{2 \tan \alpha}+l_{D 0}\left(1+\frac{q_{B}}{q_{0}}\right)\left(1-\sqrt{1-\frac{q_{0} t}{V_{D 0}}}\right) \\
x_{B}^{\prime}=x_{B}+\frac{H_{0}}{2 \tan \beta}+\frac{q_{B}}{q_{0}} l_{D 0}\left(1-\sqrt{1-\frac{q_{0} t}{V_{D 0}}}\right)
\end{gathered}
$$

Eqs. (5), (6), and (7) are new analytical solutions for the time evolution of the triangular shaped barrier island changes caused runup overwash in terms of the initial geometry of the barrier, $x_{00}^{\prime}, X_{B 0}^{\prime}$, $l_{D 0}, V_{D 0}$, and the slopes $\alpha, \beta$, as well as in terms of the seaward and landward sediment transport rates, $q_{0}$ and $q_{B}$, respectively.

The relationship for the ratio $q_{0} / q_{B}$ was assumed proportional to the ratio of the dimensionless of initial barrier crest height $\left(H_{c}\right)$ over the theoretical wave runup height $(R), H_{c} / R$. This relationship can be expresses as follows

$$
\frac{q_{0}}{q_{B}}=A \frac{H_{c} / R}{\left(1-H_{C} / R\right)}
$$

where $\mathrm{A}=0.33$ was calculated by using the experimental data as shown in Fig. 16.

Larson et al. (2005) has developed a sediment transport formula for the total eroded sediment from the dune face, $q$, by wave impact. Recently, Donnelly (2008) has added the ratio of beach crest over theoretical runup height to consider overwash cases. The formula is expressed as,

$$
q=q_{0}+q_{B}=-4 C_{s} \frac{R H_{C}}{T}
$$

where Cs is the empirical transport coefficient. By using the present laboratory experiment data the value of Cs was found equal to 0.0004 as shown in Fig. 17. Therefore, from Eqs. (20) and (21) the values of $q_{0}$ and $q_{B}$ may be calculated.

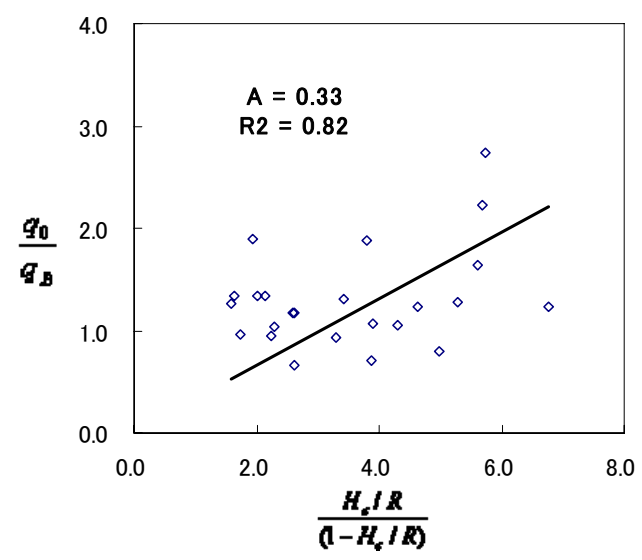

Figure16. Calibration of empirical coefficient A.

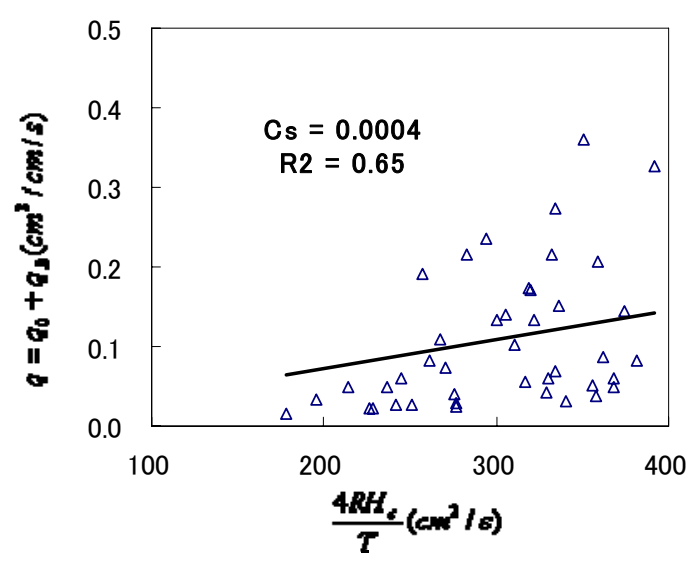

Figure 17. Total erosion volume rate versus a modified impact parameter.

\section{Analytical model results}

This new improvement of analytical model was validated against the present data sets of runup overwash cases, i.e., Cases 2, 3, 4, and 5 in Table 1. Fig. 18 shows the result of time evolution of seaward and landward locations as well as the time evolution of barrier crest height for Case 4. Fig.19 is a comparison between the analytical solution for the barrier profile change and the measured profiles. Based on these results, the time evolution of the triangular barrier profile was plotted. The results indicated that the analytical model produce predictions comparable to the experimental data. This model is useful for approximate estimates of sediment loss and remaining volume after storm events. 


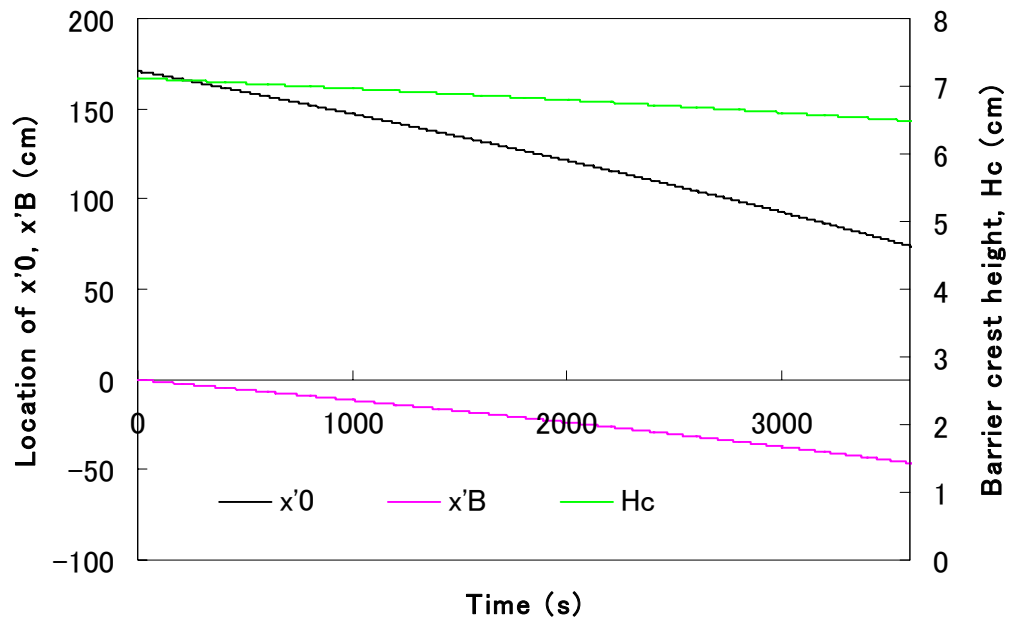

Figure 18. Time evolution of $x_{0}^{\prime}, x_{B}^{\prime}$ and $H_{C}$ locations.

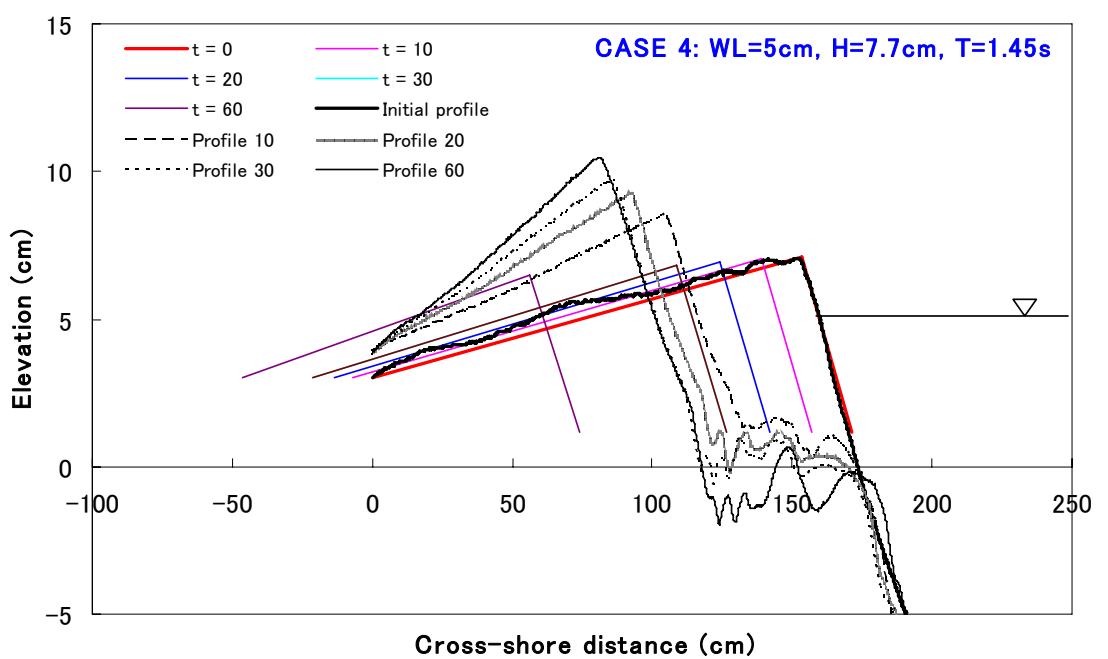

Figure 19. Comparison with the experimental data.

\section{CONCLUSIONS}

A series of laboratory experiments on the impact of storms on a sandy barrier island was carried out to increase the physical understanding of barrier responses to storms.

The results of validating a new analytical model against the obtained laboratory data indicated that the model quite satisfactorily captured the volumetric response of the profile, but the barrier crest height and location were under- and over-estimated, respectively.

\section{ACKNOWLEDGMENTS}

This study could not have been conducted without the financial support from Grant-in-Aid for Scientific Research from JSPS (No. 21-360230) and the first author is a Postdoctoral Fellow granted by JSPS (No. P09287). The authors gratefully acknowledge this support. 


\section{REFERENCES}

Baldock, T.E., Hughes, M.G., Day, K. and Louys, J., 2005. Swash Overtopping and Sediment Overwash on a Truncated Beach. Coastal Engineering 52, 2005, 633-645

Bymes, M.R., and Gingrerich, K.J., 1987. Cross-inland profile response to Hurricane Gloria, Proceedings Coastal Sediments '87, ASCE, 1486-1502.

Coastal Engineering Manual (CEM) 2002: Chapter III-3, "Cross-shore Sediment Transport Processes"

Donnelly, C. 2008: Coastal overwash: Processes and modeling, PhD Thesis, Department of Water Resources Engineering, Lund University, Sweden, 52pp.

Hancock M.W., 1994: "Experiments on irregular wave overtopping and overwash of dune", Master thesis in Civil Engineering, Faculty of the University of Delaware, Netwark, DE

Kobayashi, N., Tega, Y., and Handcock, M.W. (1996). "Wave reflection and overwash of dunes," Journal of Waterway, Port, Coastal, and Ocean Engineering, ASCE, Vol. 122, No. 3, 150-153.

Larson, M., Wise, R.A., and Kraus, N.C., 2005: "Modeling dune response due to overwash transport," Proceedings 29th Coastal Engineering Conference, World Scientific Press, 2133-2145

Larson, M.L., Donnelly, C., Jimenez, J., Hanson, H. (2009): Analytical model of beach erosion and overwash during storms, Proceedings of ICE Maritime Engineering. Vol. 162, pp115-126

Parachure, T., Dean, R.G., and Srinivas, R., 1991. Laboratory study of overwash on barrier islands. Progress Report, Coastal and Oceanographic Department, University of Florida.

Tuan, T.Q. 2007: Seasonal breaching of coastal barriers. PhD Thesis, Department of Coastal Engineering, Delft University, The Netherlands, 177pp.

Van der Wal, K., and K. Pye. 2003. "The Use of Historical Bathymetric Charts in a GIS to Assess Morphological Changes in Estuaries." Hydrographic Journal, 110. October.

Williams, P.L., 1978: Laboratory development of a predictive relationship for washover volume on barrier island coastlines, Master thesis, Department of Civil Engineering, University of Delarware, Netwark, DE, 154p. 